\title{
Breeding spring barley for ecological plasticity and adaptability in the North-Western Region
}

\author{
Lyubov Bondareva ${ }^{1}$, Dmitry Danilov ${ }^{1,2, *}$ and Lyudmila Kartashova ${ }^{1}$ \\ ${ }^{1}$ Leningrad Scientific Research Institute of Agriculture BELOGORKA, Belogorka village, 188338 Leningrad region, Russia \\ ${ }^{2}$ Saint-Petersburg State Forest Technical University named after S.M. Kirov, 194021 Saint Petersburg, Russia
}

\begin{abstract}
Creation of productive and plastic varieties of spring barley (Hordeum vulgare L.) resistant to adverse weather factors will improve the efficiency of grain production in conditions of low fertility of sodpodzolic soils in the Leningrad region in Russia. The purpose of the study was to determine the environmental plasticity and adaptation features of the new line of spring barley in comparison with the standards: Suzdalets variety (nutans variety) and Leningradsky variety (pallidum variety). The main abiotic stressors for spring barley plants are increased acidity and low supply with plant nutrients, drought followed with excess moisture at the end of the growing season. Field, laboratory, and statistical methods generally accepted for these studies were used in this work. Using the ecological plasticity index (Isp) and the generative to reproductive organs length ratio $\mathrm{ds} / \mathrm{dk}$ simplifies the task of evaluating hybrids, lines, and varieties. Genotype-environment interaction is a complex process both in its nature and in intensity. The selection of promising variety samples is aimed at isolating genotypes for which the influence of this interaction is minimal. Of particular importance in the selection of spring barley is the creation of varieties with a genetically determined mechanism of protection against adverse environmental factors.
\end{abstract}

\section{Introduction}

Barley is one of the oldest agricultural crops. Modern crop production faces a difficult task: to ensure sustainable growth in agricultural production while reducing the level of anthropogenic impact on agrocenoses, as well as to produce high quality products that can withstand competition in a market economy [1]. These circumstances pose a number of tasks for breeders:

- reducing the dependence of the yield volume and class on the influence of environmental factors;

- transferring crop production to environmentally and climatically oriented varieties and technologies;

- environmental targeting of breeding and seed production.

Spring barley (Hordeum vulgare L.) is among the four most important crops in terms of annual yield of grain from the family of Poaceae [2]. Spring barley is the main precocious grain crop for the north-west of Russia. In the Russian Federation, $60 \%$ of barley produced is used for feed purposes, as it is a good feed for livestock and poultry, containing the necessary nutrients. The problem of increasing the yield of barley, as one of the most high-yielding crops, and improving the quality of grain in modern conditions has become much more acute and has become important for agricultural producers. To achieve high yields, it is necessary to optimize the cultivation conditions of varieties taking into account soil and climatic characteristics and the use of high- quality varietal seeds that provide high yields. The problem of early maturing varieties, reducing the growing season with increasing and maintaining the productivity - the main problem of agriculture NorthWest region of Russia. Currently, it is being solved in two directions: breeding and agrotechnical development. Barley is a grain crop of early maturity and high yield potential, and it has high plasticity for growing in different geographic regions, and within a wide ecological range $[3,4]$. The adaptive genetic diversity of this crop against abiotic and biotic stresses indicates the potential of barley in the development of stress-resistant varieties [5]. Spring barley is the most important forage crop in the North-Western region. Its importance is only growing due to the rapid development of dairy and poultry farming, the widespread use of modern technologies of forage conservation: grain crushing, and grain and haylage production. The breeding of barley in the North-Western region is complicated by the diversity of soil and climatic conditions, the absence of its established local forms, and its versatile use [6]. The success of breeding also depends on the use of a large set of breeding materials in the work, a reduction in the timing of breeding new varieties, the improvement of selection methods, and the targeted formation of hybrid populations [7]. One of the urgent tasks of selection is the creation of varieties that have genetically determined mechanisms for protecting the crop from adverse environmental factors [8]. The main abiotic stressors for spring barley plants in the North-Western region are

Corresponding author: stown200@mail.ru 
increased acidity and low fertility of sod-podzolic soil, drought at the initial stage, and then excess moisture during the period of grain ripening. Main biotic stresses are fungal and viral diseases, foliar parasites such as powdery mildew (fungus Blumeria graminis (DC), spot blotch (Cochliobolus sativus Jto and Kurib), and net blotch (Pyrenophora teres f.teres Drechsl), and also stem rust (Puccinia graminis Pers). The lesser frit fly (Oscinella frit L.) is especially dangerous.

Breeders are faced with the task of creating and introducing into production of spring barley varieties which are distinguished by early maturity, high adaptation potential, and ecological plasticity. Such varieties will produce high stable yields by years ensuring a high profitability of crop production; this will provide a more complete realization of the barley crop's potential in terms of yield and product quality in the conditions of the NorthWestern region. Purpose of the study was to determine the ecological plasticity and adaptation potential of the new promising line of spring barley L1505.

\subsection{Objects}

Multi-contour land plot with an area of 1000.3 hectares, belonging to the Leningrad Scientific Research Institute of Agriculture "Belogorka" is located in the Leningrad oblast, Gatchina district. This land plot is located in the most drained northern part of the Oredezh Plateau on the Devonian sandstones that are exposed on the cliffs of the Oredezh River. The northern part of the site is slightly undulating plain, hollow down to the south, well drained, deeply incised valley. Oredezh only in the western part is suffering from temporarily excessive moisture [9]. The southern part of the site has a crossed moraine-erosion relief. The highest part of this territory is a large ridge, stretching from west to east, and to the north and south gradually turning into a plain. The plain to the south of the ridge lies much lower than to the north. In massifs dominating upland surfaces, they are almost flat, sometimes complicated by mild depressions and poorly dissected by hollow-shaped and hollow-shaped depressions, gentle hills. Soil-forming rocks are mainly moraine deposits, covering the bedrock with a cloak up to $4-6 \mathrm{~m}$ thick. The moraine is carbonate-free, but sometimes there are fragments of limestone, which almost do not affect the soil formation in conditions of normal moisture, but increase the hardness of groundwater and are the reason for the strong saturation of the soil bases of depressions. In the southeastern part of the land plot, there are tuff deposits. Most of the soils are cultivated farms. Due to easy grading, podzolic $\mathrm{A}_{2}$ horizon and often a transitional horizon $\mathrm{A}_{2} \mathrm{~B}$ profile stand out. More than three quarters of the arable land is suitable for the cultivation of grain crops. The soil in samples is sod-podzolic, slightly-argillaceous, of moderate cultural state.

\subsection{Material and methods}

The test of the new promising line L1505 was held at the seed field for competitive variety trials in the period from 2015 to 2018. In the work, there were used field and laboratory techniques with subsequent correlation and variance analysis [10]. Study of the material was carried out according to a complete selection process diagram. Phenological field observations, accounting of diseases, and harvest monitoring according to generally accepted methods were carried out [11, 12]. Analysis of variance was used in the course of a comparative analysis of the data obtained. To determine the degree of influence of weather factors on plant height, vegetation period and disease resistance, the Spearman's rank correlation method ( $\mathrm{R} \mathrm{s}$ ) was applied.

Selection of pairs for crossing was carried out taking into account the combining ability of the original forms [13]. Based on this, two directions of hybridization were used. The first direction includes the hybridization of varieties of one ecological group, which are similar in morphotype and have differences in one or two characteristics. Due to this, it is possible to quickly obtain a plant population homogeneous by morphological characteristics. It is better to use a local form adapted to the growing conditions in the capacity of a parent variety. In this case, there are no sufficiently powerful formative processes; however, the population is limited by genetic polymorphism, which narrows the range of their subsequent adaptation.

The second direction includes the hybridization of morphologically and ecologically distant forms, what leads to an increase in morphogenetic processes in the populations of spring barley and gives rise to new forms with a wide ecological potential.

Selection of plant biotypes with useful characters was carried out in combinations where one of the parents differed in the selection parameter by at least the average value of the selectable character.

In breeding practice, where much of the characters are inherited polygenically, long-term selections are carried out to stabilize the characters. According to our data, full stabilization according to such characters as springness, stem and spike length does not occur. The use of haploidic methods allows the genotype to stabilize both by androgenesis and gynogenesis, and with the use of a haloproducer $[7,13]$.

The use of biotechnology techniques in practical breeding work makes it possible to purposefully create varieties with given characteristics [13, 14]. Therefore, the varieties Baltika, Murash, Severyanin, Leningrad, Karat and the new line L1505 were created in such a way.

All characters by which the spring barley is being selected are of a complex nature, being essentially integral ones. Multi-year studies of essential characteristics determining the yield of barley varieties and hybrids, as well as plants obtained by the methods of applied biotechnology, showed a different succession character from epistasis up to complete dominance of worst shape (depression). Interactions between genes may take additive dominant to nonallelic forms. The nature of inheritance of a character depends on the number of polygens and the interaction between them in specific hybrid combinations. The components of a character are connected at the biochemical and 
physiological levels, what leads to a variation in the values of an integral character. Therefore, research of a quantitative character can be complicated by additional biochemical components having their genetic control. For example, the weight of a grain obtained from a plant is determined by the mass and number of grains per ear, their size, the number of productive metamers, the efficiency of fertilization, which, in turn, depends on the quantity and quality of storage proteins. Economic characters with a complex structure are developed during ontogenesis. This, in turn, further complicates their analysis. Therefore, it is advisable to conduct genetic analysis not for an integral feature, but for individual components, since they have a more pronounced biological character. To assess the environmental plasticity, we used such an indicator as the environmental plasticity index $\left(J_{s p}\right)$ which was calculated by the formula [5].

$$
J_{s p}=S_{s} / S_{k}
$$

where $S_{s}$ is the yield of a variety, hybrid, line $S_{k}$ is the average yield of the entire sample.

The samples with $J_{s p}>1$ are of interest for breeding and production. Comparison of various $J s p$ allows us to make a preliminary assessment of the spring barley lines, because they are relative values independent of external factors. The indicator $J_{s p}>1$ causes a wider range of distribution of the variety, its resistance to changing conditions, which are often stressful. High ecological plasticity of hybrids is ensured if the high $J_{s p}$ variety was taken as the parent form. The Suzdalets (nutans) and Leningrad (pallidum) varieties, recommended for the Northwest region, are taken as standards.

\section{Results and discussion}

The main task of breeding spring barley in the North-West region is the creation of early ripening varieties with high rates of mobilization of soil and climatic resources into the crop. Knowing in advance the reaction of the variety to the conditions of plant development, one can determine the intended distribution area. For this purpose, the term "plasticity" is used in selection practice. Plasticity is understood as the ability of a variety to change a separate attribute in such a way that its integral expression remains at a certain level. This is the main adaptive property of an organism. Environmental plasticity is an overall reaction of the variety to changes in the soil and climatic environment.

According to our data, $12-20 \%$ of the variance properties are due to varietal factor, 21-29 \% are caused by plant developmental adaptability and more than
$25 \%$ of the variance properties are due to the interaction "grade - environment". Line 1505 (variety pallidum) was obtained with the participation of the Belogorsky variety with a high Jsp (up to 1.7 units) as the parent form. It was isolated from a hybrid population from the crossing of three varieties of different ecological and geographical origin: Belogorsky (Russia), WW 6320 (Sweden), Cherkassy 426 (Ukraine). Applied biotechnology methods have been used in the course of its creation. This line is a doubled haploid. We have obtained regenerants evaluated in selective media for resistance to increased acidity of the soil and drought.

Table 1 shows economically valuable and adaptational characteristics of L1505 compared with the standards. The "Leningradsky" variety is a standard for early ripeness in the North-Western region.

Weather conditions during the years of research were contrasting. In 2016, the average air temperature $\left(\mathrm{t}_{\text {aver }}{ }^{\circ} \mathrm{C}\right)$ during growing period was $15.4^{\circ}$, that is $1.7^{\circ} \mathrm{C}$ above normal. Total precipitation $(\Sigma \mathrm{Nmm})$ was $358.2 \mathrm{~mm}$, or $77 \mathrm{~mm}$ above normal. The weather was hot with frequent rains. The year of 2017 was characterized by cool weather, $\mathrm{t}$ aver ${ }^{\circ} \mathrm{C}$ was $1{ }^{\circ} \mathrm{C}$ below normal, and $\Sigma \mathrm{Nmm}$ was $320 \mathrm{~mm}$, i.e. close to the mean annual value. The deficit of total effective temperatures was $195{ }^{\circ} \mathrm{C}$. In 2018, the yield was formed under adverse conditions. At the critical periods of their development (tillering, leaftube formation, earing), plants experienced stress from increased temperature and lack of moisture, $\mathrm{t}$ aver. ${ }^{\circ} \mathrm{C}$ was above climatic norm by $2^{\circ} \mathrm{C}$.

Table 1. Agrobiological characteristics of spring barley varieties, 2016-2018 years

\begin{tabular}{|c|c|c|c|c|}
\hline Variety, hybrid & $\begin{array}{c}\text { Productivity } \\
\mathrm{kg} 3 \mathrm{~m}^{-2}\end{array}$ & $\begin{array}{l}\text { Vegetation } \\
\text { period, days }\end{array}$ & Stem & $\begin{array}{l}\text { Teight, } \\
\mathrm{n}\end{array}$ \\
\hline Suzdalets, st. nutans & 3.1 & 85 & & \\
\hline Leningrad, st. & 2.7 & 74 & & 2 \\
\hline L1505 pallidum & 3.6 & 75 & & 5 \\
\hline \multirow{2}{*}{\multicolumn{2}{|c|}{$\begin{array}{l}\text { Resistance to the Helminthosporium } \\
\text { disease, } \%\end{array}$}} & \multirow[b]{2}{*}{$\begin{array}{l}\text { Variety, } \\
\text { hybrid }\end{array}$} & \multicolumn{2}{|c|}{ units } \\
\hline & & & Isp & $\frac{\mathrm{ds}}{\mathrm{dk}}$ \\
\hline Suzdalets, st. nutans & $10-15$ & 42.6 & 1.04 & 10.0 \\
\hline Leningrad, st. pallidum & $15-20$ & 36.0 & 1.0 & 12.1 \\
\hline L1505 pallidum & $10-15$ & 40.8 & 1.2 & 10.4 \\
\hline
\end{tabular}

The calculation of paired correlations of yield, duration of the growing season, stem length of barley varieties with temperature and amount of precipitation showed the average negative correlation of yield with $\mathrm{t}_{\text {aver. }}{ }^{\circ} \mathrm{C}(\mathrm{R}=-0,37)$ and a high inverse correlation of the vegetation period with $t_{\text {aver. }}{ }^{\circ} \mathrm{C}(\mathrm{R}=-0.88)$ for the Suzdalec variety. For the short-season variety "Leningradsky", it was found that the variety has negative correlation between yields and temperature $(\mathrm{R}=-0.48)$ which is more significant than for other ones. 
Its average feedback found for stem length with temperature was $(\mathrm{R}=-0,34)$. The dependence of the yield and the stem length on $t_{a v e r}{ }^{\circ} \mathrm{C}(\mathrm{R}=-0,26 ; \mathrm{R}=-0.12)$ for the line L1505 has not been revealed. The determining factor for Suzdalets is a thermal regime. This variety is more demanding to moisture. For the Leningradsky variety, the yield was largely determined by the air temperature. The productivity of the new line L1505 was less dependent on weather conditions, and it was most resistant to abiotic stressors and moisture conditions. Calculation of the rank correlation coefficient for resistance to such abiotic stressors as high (2018) and low air temperatures (2017) and to humidity conditions was carried out. The calculation of Spearman rank correlation $\left(R_{s}\right)$ coefficient has revealed that the line L1505 is definitely more resistant to the dark-brown patch than the variety Leningradsky. At the level of $p=0.05, R s=0.857$, with a critical value of $R_{s}=0.780$.

The average yield of L1505 over three years of research is $3.6 \mathrm{t} / \mathrm{ha}$ and was significantly higher than that of the standards $\left(\mathrm{F}_{\text {table. }}=2.24<\mathrm{F}_{\text {act. }}=5.35\right.$ with $\left.P_{01}=0.15\right)$. Its average growing season is 75 days. The line is earlier-maturing than the Suzdalets variety, and is at a level of the Leningradsky variety by this property. Its resistance to lodging and gelmintosporiosis is at the level of the Suzdalets variety.

The ecological plasticity index (Jsp) of spring barley varieties varied depending on weather conditions. Through all the years of research, this indicator did not fall below 1.0 for L1505, what indicates its high ecological plasticity. For three years, Jsp for the Suzdalets variety amounted to 1.04 units, and 1.2 units for line L1505. For breeding purposes, it is meaningful to use varieties and hybrids which have Jsp $>1$. If Jsp $<1$, then the study of the hybrid is no longer appropriate.

Mass of 1000 grains for multi-row barley is usually lower than for double row. For L1505, it was 40.8, i.e at the level of the Suzdalets variety $(42.6 \mathrm{~g})$ and significantly higher than for the Leningradsky variety $(36.8 \mathrm{~g})$ (Least average experience error $_{05}=1.7 \mathrm{~g}$ ). The plant stem length is one of the signs of its resistance to lodging. For an average of three years, it was $70 \mathrm{~cm}$ for the Suzdalets variety, and $75 \mathrm{~cm}$ for the L1505. Factor analysis has shown that the height of Suzdalets variety plants had a more significant effect on yield $\left(R_{s}=0.97\right)$. As a rule, in high-yielding varieties an ear makes up a significant part of the stem in terms of weight. In this connection, the ratio of the length of the stem to the length of the ear ds/dk is of particular importance. This indicator characterizes not only lodging resistance, but also plant productivity.

\section{Conclusions}

1. For breeding purposes, combinations with a share of a stem length equal to 10 or less units are of interest. The character manifestation nature is strongly influenced by growing conditions, therefore, the variability that is already determined genetically by at least two ear and straw systems, may increase.
2. The stem length to the ear length ratio ( $\mathrm{ds} / \mathrm{dk}$ ) equal to 10 units and less serves as a confirmation of the adaptive potential of the variety or hybrid. The strategy for creating spring barley varieties should be aimed at reducing the stem share in the total length of the spear. Such a ratio of generative and reproductive characters will allow the most productive stems to form and ensure an increase in yield. As for the Suzdalets variety, ds / dk annual average value was 10.0 units, and for L1505 it was 10.4 units.

3. In the selection work carried out, the authors isolated and investigated hybrids, in which the length of the stem is reduced due to the length of the two upper internodes, and the number of internodes is not reduced.

4. The conducted studies allow us to conclude that the new line L1505 produces a higher yield, is distinguished by early ripening, ecological plasticity, and adaptation potential. The high index of environmental plasticity causes a fairly wide area of distribution of the line L1505, its stability, the ability not to reduce the adaptation indicators in changing conditions, often being stressful.

\section{References}

1. M.V Arkhipov, T.A Danilova, S.M. Sinitsyna, The state and prospects of development of the grain industry in the North-West Federal District of the Russian Federation, In: Scientific support for the development of grain production in North-West Russia. Proceedings of meetings of the Presidium and Scientific Coordinating Council for Agriculture and Plant breeding in the Northwestern Regional Scientific Center - SPb. 4-15, Propulsion physics (EDP Sciences, Les Ulis, 2009)

2. N. Gozukirmizi, E. Karlik, Barley (Hordeum vulgare L.), Improvement Past, Present and Future (Makoto Kanauchi, Intech Open, 2017)

3. R.P. Ellis, B.P. Forster, D. Robinson et al., Wild barley: a source of genes for crop improvement in the 21st century? J. of Experimental Botany 51(342), 9-17 (2000)

4. A. Kolodinska Brantestam, R. von Bothmer, C. Dayteg et al., Genetic diversity changes and relationships in spring barley (Hordeum vulgare L.) germplasm of Nordic and Baltic areas as shown by SSR markers, Genet. Resour. Crop Evol. 54(4), 749-758 (2007)

5. S.A. Eberhart, W.A. Russel, Stability parameters for comparing varieties, Crop Sci. 6, 36-40 (1966)

6. K. Hakala, L. Jauhiaine, S.J. Himanen et al., Sensitivity of barley varieties to weather in Finland, J. of Agricult. Sci. 150(2), 145-160 (2012)

7. M.V. Ivanov, Spring barley resistance to adverse environmental factors (Luga, 2004), $134 \mathrm{p}$.

8. O.B. Batakova, V.A. Korelina, N.V. Ivanova, A.V. Anisimova, Testing of new early ripening barley lines in the conditions of the Northern region of the Russian Federation, in: Works on appl. 
botany, genet. and select. 177(2), 34-44 (St. Petersburg, 2016)

9. L.M. Bondareva, T.N. Radyukevich., L.I. Kartasheva, D.A Danilov, Complex resistance to leaf diseases of spring barley in Leningrad region, Advances in Engineering Research, 151, 1-7 (Atlantis Press, 2018)

10. B.A. Dospekhov, Field testing methods (with the basics of statistical processing of research results (Agropromizdat, Moscow, 1985), $351 \mathrm{p}$.

11. P.F. Garkavy, The study of quantitative characters in barley hybrids obtained by crossing varieties of different ecotypes for breeding purposes, The report of the All-Union Acad. of Agricult. Sci. (Kolos, Moscow, 1980), no. 5, pp. 3-5

12. Guidelines for the study and preservation of the world collection of barley and oats) (VNIIR named after N.I. Vavilov, St. Petersburg, 2012), 63 p.

13. O.N. Kovaleva, N.N. Ivanova, New source material for barley breeding in Northwest Russia, Works on appl. botany, genet. and select. 171, 284-286 (St. Petersburg, 2013)

14. M.V. Ivanov, N.V. Ivanova, Varieties of spring barley for the North-West of Russia, Works on appl. botany, genet. and breed. 162, 78-83 (St. Petersburg, 2006) 